\title{
What happens to gazelles? The importance of dynamic management strategy
}

\author{
Simon C. Parker • David J. Storey • \\ Arjen van Witteloostuijn
}

Accepted: 12 November 2009/Published online: 5 January 2010

(C) The Author(s) 2010. This article is published with open access at Springerlink.com

\begin{abstract}
The starting point of this study is Gibrat's Law, which is contrasted with strategic management. This logic is subsequently applied to a group of remarkably dynamic, high-growth firms: gazelles. Strategic management theory emphasises the importance of firms adjusting strategies in response to changes in the external environment. In our study, it is used to explain several key empirical findings using a novel British data set containing information on more than 100 gazelles. These findings help explain: (1) why Gibrat's Law of random firm growth processes does not generally hold, (2) which strategy and environmental variables have a predictable influence on firm performance and (3) why routine application of 'best practice' strategies is unlikely to foster firm growth in a changing economic environment. In so doing, this paper contributes to the large body of literature on small-firm growth.
\end{abstract}

\footnotetext{
S. C. Parker

University of Western Ontario, London, ON, Canada

D. J. Storey

School of Business Management and Economics, University of Sussex, BN1 9RH Brighton, UK

A. van Witteloostuijn $(\bowtie)$

Faculty of Applied Economics, Department of Management, Antwerp Centre of Evolutionary Demography, University of Antwerpen, Prinsstraat 13, 2000 Antwerpen, Belgium

e-mail: arjen.vanwitteloostuijn@ua.ac.be
}

Keywords Firm growth - Gazelles · Gibrat's Law · Strategic management theory · Strategy variables

\section{Introduction}

What explains differences in growth rates between firms? There have been many attempts to answer this question since at least the time of Gibrat (1931), who proposed in his famous 'Law' that the widely observed positively skewed distribution of firm sizes can be explained in terms of firm growth rates being independent random variables. If firm growth is a random variable, then three outcomes are excluded: first, firms of a given size will grow faster (or slower) than other sized firms; second, firms that grow faster (or slower) in one time period will grow faster (or slower) than in a later time period; third, there will be factors that powerfully and consistently explain firm growth performance. This paper directly tests outcomes two and three.

In his review of 'Gibrat's Legacy', Sutton (1997) concluded that half a century of testing had revealed several statistical regularities that were incompatible with firm growth being a purely random processmost notably that small firms appeared to grow faster than large ones and that growth rates were serially correlated. For example, Hart and Oulton (1996) 
found the smallest sized firms grew fastest, and Singh and Whittington (1968) for the UK, and Wagner (1992) for West Germany both found that those firms growing faster in one period of time were more likely than others to have an above-average growth rate in subsequent periods. ${ }^{1}$

However, a more recent review by Coad (2009), covering more than 20 studies, concludes that the overall evidence on serial correlation of growth rates, both positive and negative, is mixed. Highly relevant for the current paper is his interpretation that serial correlation is more likely to be negative for small firms and for firms experiencing extreme growth rates (either positive or negative). But what is consistently confirmed in empirical work is that there are firms that do grow exceptionally fast and which have become large in a relatively short space of time. Such firms are referred to in the literature as 'gazelles' (Acs and Mueller 2008).

Gazelles and Gibrat's Law are of interest to three constituencies. The first are scholars from within the strategic management tradition who seek to link individual firm performance to strategy. For these individuals, implying that growth rates are random is incompatible with the evidence that some businesses are better managed than others-and hence perform better. Gazelles, therefore, because of their exceptional growth rates, are of extreme interest as evidence in support of the main assumption of strategic management: that strategy matters. A second group interested in gazelles are management consultants. Since gazelles frequently become a 'brand', about which awareness is high, there is a value for management consultants in being able to distill lessons, or 'best practices', for others from observing the performance of gazelles (Peters and Waterman 1982). The third group interested in gazelles are public policy-makers responsible for economic and, in particular, employment policy. Jovanovic (2001) reported that, immediately prior to the dot-com collapse, four U.S. gazelles-Microsoft, Cisco Systems, MCI and Dell-had a market valuation equivalent to $13 \%$ of the U.S. gross domestic product, despite not having existed 20 years previously. Therefore, gazelles are important because of

\footnotetext{
$\overline{1}$ Lotti et al. (2009) provide a helpful review of recent findings on Gibrat's Law.
}

their disproportionate contribution to wealth and job creation.

The central question posed by this paper is whether the clear presence and economic significance of gazelles is compatible with Gibrat's Law or, instead, whether it reflects the expectations of the strategic management literature. To address this question, we adopt a novel approach. We first identified a group of exceptionally fast-growing businesses (gazelles) over one time period, and then we tracked the same firms over a second time period. ${ }^{2}$ Rejecting Gibrat's Law implies that firms which grow faster (or slower) in one time period will grow faster (or slower) in a later time period. Our broad finding is that the growth rate of the initial gazelles group is substantially lower in the second time period. This implies that growth is not serially correlated, which supports Gibrat's Law.

We noted above that Gibrat's Law is incompatible with evidence of factors that powerfully and consistently explain firm growth performance. To address this incompatibility, we formulate two tests. First, we identify five areas of strategy shown by other scholars to be important in promoting growth: human resource management, innovation and technology, administration and governance, marketing and sales, and corporate strategy. We then examine the extent to which actions, grouped within these five areas, explain gazelle growth. We find, as do many other researchers, a number of significant strategy-growth relationships, implying a rejection of Gibrat's Law.

Our second, and more challenging, test for the presence of 'powerful and consistent' factors that explain fast growth is to see if the same factors that explained growth in the first period continue to explain growth in the second. Our central finding is that while there are links between strategies and performance, the same factors do not 'powerfully and consistently' influence performance in the same way in both periods. One of the key findings is, for example, that the gazelles that sell ownership to others subsequently perform worse than gazelles that do not share ownership. This finding could reflect the

\footnotetext{
${ }^{2}$ We do not imply that the tracking of a group of firms over time is novel. This, for example, is the approach used by Lotti et al. (2009). The novelty of our approach is to explicitly identify the gazelles in one period only to then track their performance over time.
} 
importance of having a management strategy that is dynamic and flexible, which is very much in line with strategic management logic.

This paper therefore differs substantially from prior work on gazelles which has taken a group of firms and compared those that grow fast over a period of time-the gazelles-with the remainder of the sample. Our approach is different. Instead of relying on the rest of the sample as our 'control group', we use the same gazelles, i.e., those from the earlier time period, as the comparator. This approach enables us to directly test for growth rate serial correlation and for whether there are powerful and significant factors that explain firm growth rates over time.

\section{Literature review}

Table 1 provides a synthesis of a number of the studies that have been undertaken to examine fast growth in primarily small- and medium-sized enterprises (SMEs). The studies are chosen to be illustrative rather than comprehensive, ${ }^{3}$ and to reflect country diversity, the methodological approaches adopted, and the results obtained.

A first issue that emerges from Table 1 relates to definitions, highlighting the variety of different definitions that have been used for 'fast growth' firms, or 'gazelles'. For example, the study by Delmar et al. (2003) alone used 19 measures of growth. Clearly, the first source of variability is the appropriate metric for growth. In this table, the reported studies have used sales, employment, profitability, or subjective assessments on the part of the owners. A second issue is defining precisely what constitutes 'fast growth'. Where sales are taken to be the metric, fast growth is in the region of $20-30 \%$ per annum as a minimum. Alternatively, it includes multiple measures relating to metrics other than sales. A third source of variation is the time period over which the fast growth is achieved. Some studies examine changes taken over 1-3 years, whereas others focus on growth over a decade or more. A fourth issue is whether fast growth is expected to be achieved each and every year over the period, or whether growth rates may fluctuate so as to achieve

\footnotetext{
${ }^{3}$ Helpful recent overviews of SME growth rates are provided by Davidsson et al. (2007), Henrekson and Johansson (2009), and Wiklund et al. (2009).
}

only a certain average growth percentage over the period under consideration. A fifth definitional issue relates to whether growth is organic or whether increases in sales can be achieved by acquiring other businesses. Most studies make no distinction between these types of sales increase, but others view growth through acquisition as, in some ways, less desirable, ${ }^{4}$ and hence not as part of the definition of 'fast growth'. Our purpose in reporting this diversity is not to imply that one approach is preferable to others, or even to set out the criteria upon which it is desirable to judge the chosen fast growth definition. Instead, it is to emphasise that, given this diversity, the comparability of findings across studies is likely to be influenced by these definitional considerations. It also provides a context for the definitional choices made in this paper.

Perhaps in part because of this diversity of definitions, there are both some consistencies and many inconsistencies in this literature. We begin by summarising the key consistencies. First, whilst there is evidence that rapidly growing enterprises are more heavily concentrated in the technologically sophisticated sectors, they are by no means exclusively concentrated within these sectors. For example, Bishop et al. (2009) report that in the UK only 7\% of high-growth firms are in high-technology sectors. This is also supported by U.S. evidence provided by Acs and Mueller (2008), indicating that an exclusive focus upon technology-based sectors would exclude consideration of the vast bulk of gazelles. Instead, such enterprises are found in almost every sector, almost irrespective of the overall performance of that sector. Second, the patterns of growth amongst gazelles are extremely volatile. Few appear to grow in a consistent linear manner (Delmar et al. 2003; Garnsey et al. 2006). Rather, growth is characterised by dynamic bursts over a short period of time, but then often followed either by decline or by a considerable slowing of growth rates (Hull and Arnold 2008). Such volatility appears to be particularly characteristic of younger and smaller firms. This growth rate pattern is compatible with the observation of Coad (2009) that

\footnotetext{
${ }^{4}$ On the grounds that, from the national viewpoint, there is no additionality if one firm simply obtains the sales of another firm through acquisition. However, even this accounting statement can have economic significance if the acquiring firm makes more efficient use of the assets of the acquired business.
} 


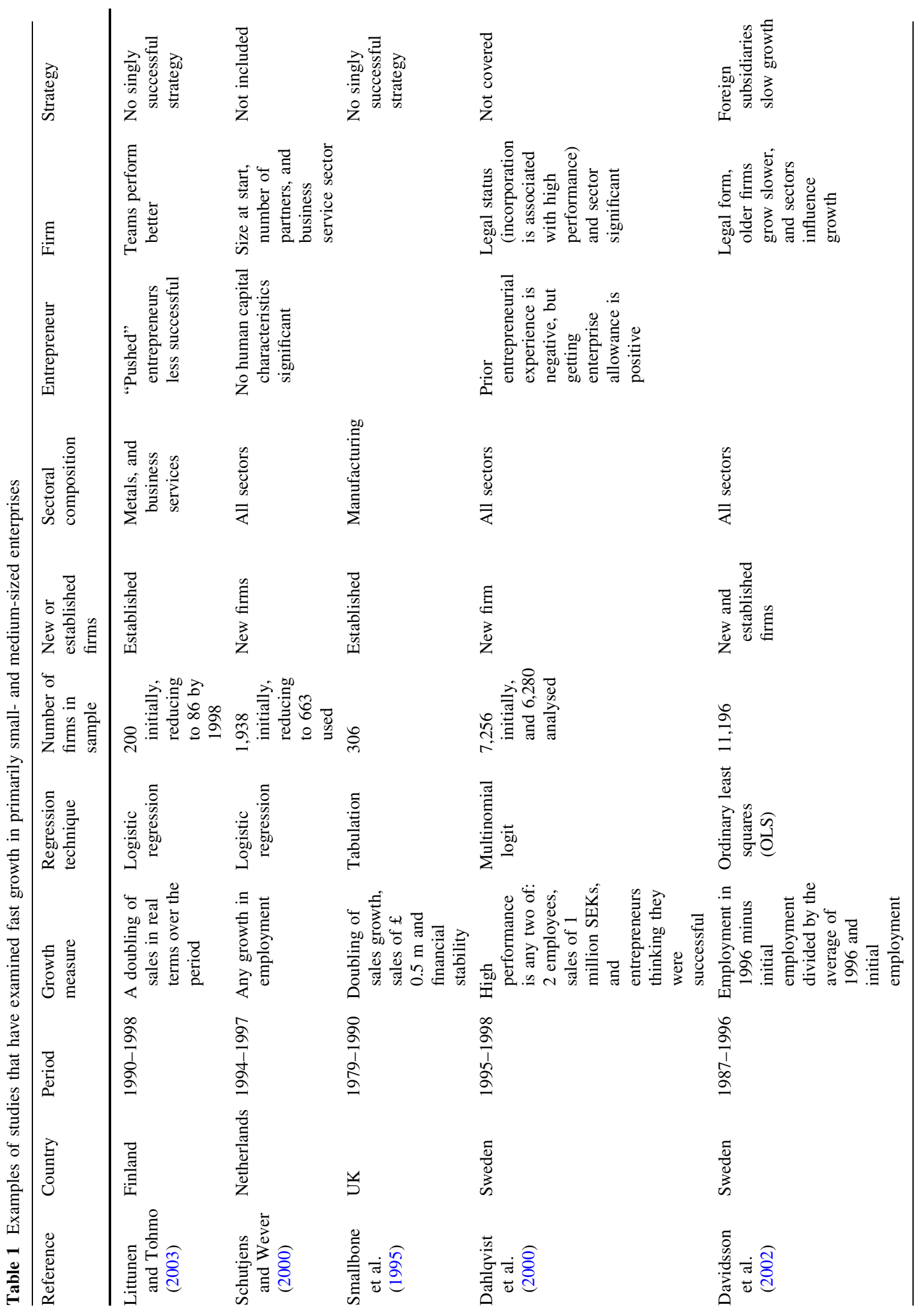




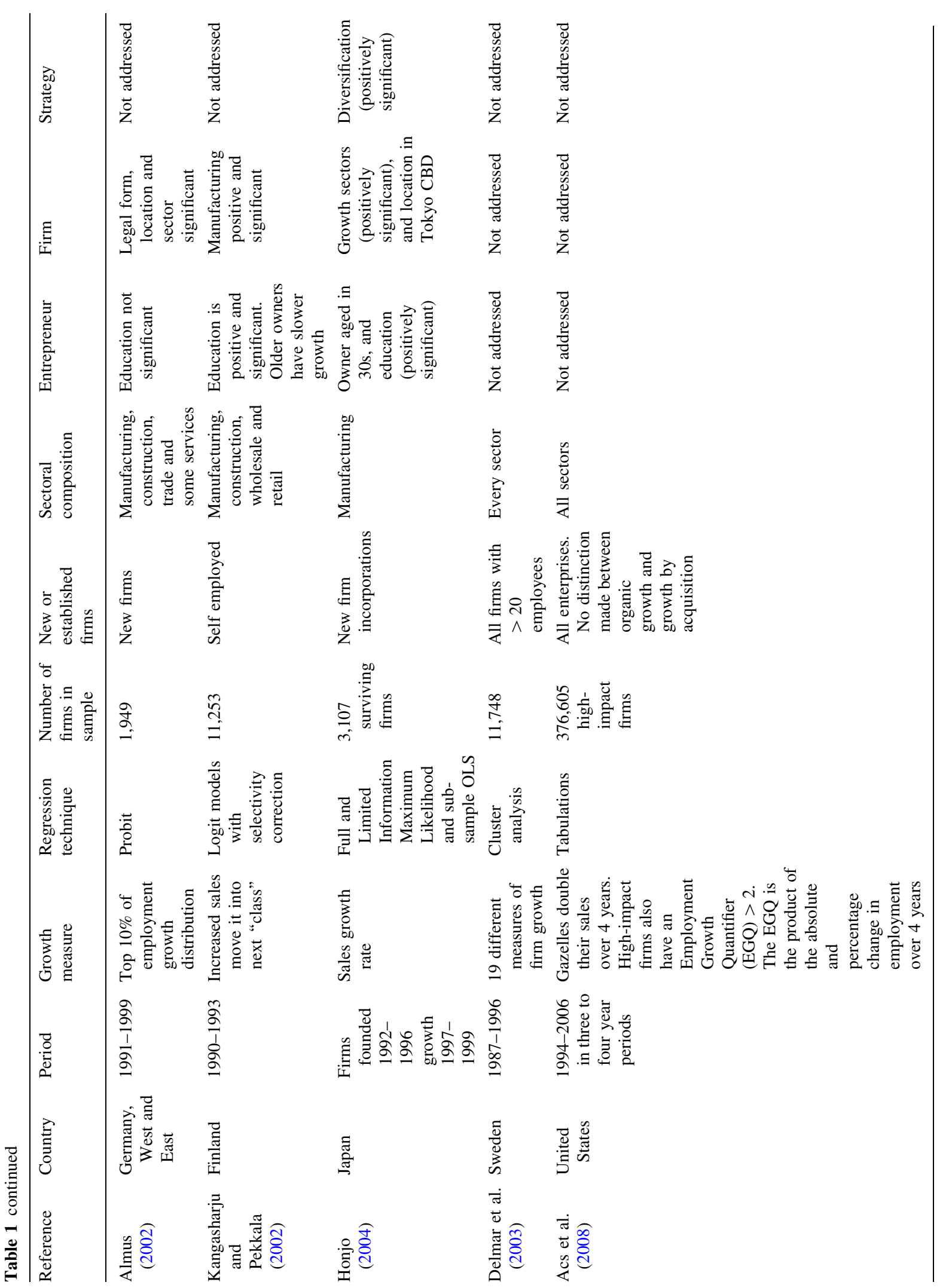


serial correlation appears to be negatively significant for smaller and younger firms, yet positive for older and larger firms. Third, whilst many firms show gazelle-like performance for short periods of time, very few continue that growth into the medium term. Where this has been examined, the most typical pattern is for former gazelles to return to the industry average (Acs et al. 2008).

The empirical literature on exceptionally fast growth amongst SMEs has generally combined both young and small firms. To capture both effects, Storey (1994) makes a distinction between three influences: first, the pre-start characteristics of the business (most notably those of the founders/owners); second, the factors present when the business starts (the sector, location, and legal form); third, the poststart characteristics of the business (most notably its strategy in the marketplace). These influences are reflected in Table 1. Whilst some of the firms in our sample are young, many are not. One, for example, has more than a century of trading history, but has only very recently experienced gazelle rates of growth. For this reason, we place less focus on the pre- and at-start factors and instead concentrate on post-start or strategy factors.

Within this group of influences, four functional strategies have been particularly widely analysed, with evidence provided for their effect on firm performance: human resource management (HRM) (Huselid 1995; Storey 2003); innovation and technology (Itami and Numagami 1992; Stam and Wennberg 2009); administration and governance (Naman and Slevin 1993; Daily et al. 2002); and marketing and sales (Slater and Olson 2001; Matsuno et al. 2002). Nevertheless, despite numerous studies demonstrating relationships between the growth of firms and the influences identified above, the strong impression remains that the vast bulk of growth cannot be explained by the current theoretical frameworks. It is important to recognise that the extent to which these factors explain variations in growth is extremely modest indeed. Coad (2009) shows that, of the 12 studies addressing this issue, eight report $R^{2}$ values of below $10 \%$ and six report values of $5 \%$ or less. Based on this evidence, the hypothesis that growth is a random walk cannot easily be dismissed. It is generally the case that the bulk of these studies rarely include strategy factors. However, where they do, the $R^{2}$ metric is rarely used. One of our contributions is 
therefore to provide a more comprehensive model of firm growth, thereby limiting omitted variable bias but also assessing the contribution of strategy to firm growth amongst medium-sized enterprises.

\section{Three-fold contribution}

In this study, given the context of the above literature review, we seek to contribute to three issues that stand out as critical in the gazelles literature. First, we estimate models of firm survival and firm growth in order to examine which — if any-features of firms and their environment significantly explain performance variation. As we will explain below in detail, we will run analyses with either firm survival or firm growth as the dependent variable, both for econometric and substantive reasons. As far as independent variables are concerned, our ambition is to estimate a comprehensive performance model in order to limit the bias of the omitted variables that characterises so many of the earlier studies. As our data do not cover pre-startup characteristics, we are limited in what we can do here. However, we tried to collect information on a wide variety of at-startup and post-startup characteristics as well as information on the external environment. First, we include information on a series of structural variables that relate to at-startup characteristics, such as geographical location and firm age. Second, we have data on five types of strategies, relating to poststartup characteristics: corporate strategy, administration and governance, human resource management, innovation and technology, and marketing and sales. Jointly, we refer to these as management strategies. Third, we collected firm-specific information on the external environment, measuring market attractiveness, bargaining power, and market competitiveness.

Secondly, we estimate our comprehensive growth model to examine Gibrat's Law. Gibrat's Law states that the rate of growth of a firm in one period is independent of the firm's size and, therefore, has no influence on the firm's growth in subsequent periods. Thus, if we measure firm size by (for example) turnover, which we denote at time $t$ by $T_{t}$, then Gibrat's Law states that $\Delta \ln T_{t}$ is random and independent of $\Delta \ln T_{t \pm \tau} \forall \tau$, where $\Delta$ is the first difference operator, 'In' denotes the natural logarithm, and $\tau=1,2, \ldots$. In contrast, the strategic management literature explicitly assumes that firm growth is non-random, with some firms performing consistently better than others, at least in part because they adopt more appropriate management strategies given the environmental context in which they are applied. Consequently, Gibrat's Law offers a nice benchmark against which to test the claim of strategic management proponents that strategy matters (McGahan and Porter 2003).

Thirdly, and related to our investigation of Gibrat's Law, our final contribution is motivated by a thoughtexperiment of the following kind. It is sometimes suggested, usually in the popular management press and in the world of consultancies (Sorge and van Witteloostuijn 2004), that there often exist simple best practice management strategies that firms can and should adopt to enhance their performance. This would imply there are best practices, or static management strategies, that facilitate performance, including firm growth, across time. Put differently, this logic implies that the set of management strategies that contributed positively to gazelle-like growth in period $t$ will also do so in period $t+1$. It is this kind of argument that dominates much consultancy practice. Our benchmark hypothesis, which is to explore this issue, is that the adoption of static management strategies will not increase a firm's long-run growth rate. In contrast, dynamic management strategies are needed, which are flexibly adapted over time in response to changing circumstances.

\section{The data}

Data were collected in three steps over real time. The first step at time $t$ was to identify the population of non-subsidiary, medium-sized and UK-owned companies (so-called 'Middle-Market' firms) and then to identify those that had enjoyed rapid sales growth during the previous 4-year period, i.e., between $t$ and $t-4$. The second step was to conduct, in year $t$, a telephone interview with the Chairmen/Chief Executives of these companies. The third step was to track the changes in these companies until $t+5$.

\subsection{Step one}

The data were taken from the ICC/One Source database. The sample was drawn in late 1995. The purpose was to examine the factors influencing the 
performance of UK 'Middle-Market' companies. These were defined as limited companies that were not subsidiaries and which, in their most recent financial year, had sales of between $£ 5$ million and $£$ 100 million. To measure firm growth, all companies in the sample were also required to have at least four previous years of financial records. The ICC/One Source database identified 7,203 companies that satisfied these criteria. These companies were then ranked in terms of the change in compound annual sales over the prior 4 years. Those companies whose annual sales growth exceeded $30 \%$ per annum were defined to be the group of interest. They constituted 9.8\% of the Middle-Market population and are referred to as 'Ten Percenters' in this paper. In total, 708 Ten Percenters were identified. The ICC/One Source database includes primarily financial data in the form of profit and loss accounts and balance sheets, together with details on directors and share ownership. To obtain additional information about a firm's strategies, we contacted a random sample of these firms directly.

\subsection{Step two}

Interviews were conducted in November 1996 to obtain an understanding of a wide array of management strategies for a sample of these firms. These interviews took place with the 156 firms (among 708) deemed to be eligible, a crude response rate of $22 \%$. $^{5}$ The telephone interview with the Chairman/Chief Executive (mostly) focused on their views of the factors influencing sales growth in the prior 4 years, management strategies, and broader environmental conditions.

\subsection{Step three}

The companies were then tracked until 2001, using the Fame database. Like the ICC/One Source, Fame utilises data submitted to Companies House. The status of the company in 2001 was assessed so that a distinction could be made between those companies that survived and those that did not. A second

\footnotetext{
5 In practice, the response rate was significantly higher since amongst the 708 firms, many turned out to be ineligible, most frequently because they were not actually independent or not UK owned.
}

distinction was made amongst the survivors between those that continued to be independent and those that were acquired. Financial data for survivors were also available up to 2001. Hence, 5 years of performance data were available following the initial identification of the firm in 1996. Of the 156 potential cases, 121 were used in this analysis. Sample attrition occurred because, with the additional information, 12 cases were ultimately deemed to be ineligible. ${ }^{6}$

We use two measures of firm performance in the empirical exercise: firm status at the end of the sample period (i.e., 2001) and the percentage average annual turnover growth over the 1992-1996 and 1996-2001 period, respectively. Firm status (defined below) is a key measure of organisational performance, while also serving to control for possible survivor bias in the growth analysis (Sutton 1997). That is, firms that survive tend, on average, to have higher growth rates, so estimates of firm growth equations need to take account explicitly of possible sample selection bias.

We now define firms' observed status in 2001. First, firm $i$ 's sales turnover in 2001 is denoted by $T_{i}$ if it survives until then. Status can then take one of five values for firm $i$ :

$z_{i}:= \begin{cases}0 & \text { if } \quad i \text { is liquidated } \\ 1 & \text { if } \quad T_{i}<£ 5 \mathrm{~m} \\ 2 & \text { if } £ 5 \mathrm{~m} \leq T_{i}<£ 100 \mathrm{~m} \\ 3 & \text { if } £ 100 \mathrm{~m} \leq T_{i} \\ 4 & \text { if } i \text { is acquired }\end{cases}$

Henceforth, we refer (merely for brevity) to status groups 1, 2, and 3 as 'small', 'medium' and 'large', respectively. Not too much should be read into these appellations as a size discriminator. Nor can the above status schema be regarded as an ordering, given the presence of group 4 . The penultimate row of Table 4 below will present data on the frequencies of each status group. Our other measure of performance is firms' turnover growth rate over 1992-1996 and 1996-2001, respectively. These rates are calculated using the whole array of turnover values for each firm, a standard practice in strategic management research on organisational growth.

The first and second parts of Table 2 suggest empirical counterparts to the five management

\footnotetext{
${ }^{6}$ The most frequent reason for ineligibility was that it became clear that the company had never satisfied the requirement of being independent and UK owned.
} 
Table 2 The variables

\begin{tabular}{|c|c|}
\hline Concepts/variables & Sources/questions \\
\hline \multicolumn{2}{|l|}{ Management strategies } \\
\hline \multicolumn{2}{|l|}{ Human resource management (HRM) } \\
\hline Percentage workforce shares & $\begin{array}{l}\text { Approximately what percentage of the total workforce currently own shares or hold } \\
\text { options in the company? }\end{array}$ \\
\hline Workforce training & Can you give your best estimate of the company's total annual training budget? \\
\hline Responsibility for HRM & Is there a (board) director with specific responsibility for staff training and development? \\
\hline \multicolumn{2}{|l|}{ Innovation and technology } \\
\hline Recent innovations as $\%$ of sales & $\begin{array}{l}\text { Approximately what percentage of your current sales come from new products or services } \\
\text { introduced in the last } 3 \text { years? }\end{array}$ \\
\hline Developing new product(s) & $\begin{array}{l}\text { Are you currently developing any new product(s) or service(s) for introduction in the next } \\
2 \text { years? }\end{array}$ \\
\hline $\begin{array}{l}\text { Responsibility for Research and } \\
\text { Development (R\&D) }\end{array}$ & $\begin{array}{l}\text { Do you have a director or manager with specific responsibility for developing new } \\
\text { products or services? }\end{array}$ \\
\hline \multicolumn{2}{|l|}{ Administration and governance } \\
\hline Single enterprise & Is this organization a single corporate body or a group of companies? \\
\hline Percentage directors' shares & What percentage of shares in the company is currently held by directors or their families? \\
\hline Percentage institutional shares & What percentage of shares in the company is held by institutional investors? \\
\hline \multicolumn{2}{|l|}{ Marketing and sales } \\
\hline Use of customer surveys & $\begin{array}{l}\text { Do you use customer market surveys to evaluate the quality of your company's main } \\
\text { product or service? }\end{array}$ \\
\hline Use of customer complaints & $\begin{array}{l}\text { Do you use the level of customer complaints to evaluate the quality of your company's } \\
\text { main product or service? }\end{array}$ \\
\hline Use of marketing department & Does your company have a marketing or sales department? \\
\hline \multicolumn{2}{|l|}{ Corporate strategy } \\
\hline Sells to other companies & $\begin{array}{l}\text { Approximately what percentage of your current sales come from sales to other companies } \\
\text { (including retailers and wholesalers)? }\end{array}$ \\
\hline International market & Is the main market you serve international? \\
\hline Main product as $\%$ of sales & What percentage of sales are accounted for by your main product or service? \\
\hline \multicolumn{2}{|l|}{ External environment } \\
\hline \multicolumn{2}{|l|}{ Market attractiveness } \\
\hline Sales risk & Natural logarithm of the standard deviation of sales in millions of British pounds. \\
\hline Past demand growth & $\begin{array}{l}\text { Has spending by customers on your main product or service increased a lot in the last } 4 \\
\text { years? }\end{array}$ \\
\hline \multicolumn{2}{|l|}{ Bargaining power } \\
\hline Customer base over 1,000 & Approximately how many customers do you currently have? \\
\hline Increased sales concentration & Over the last 4 years has the percentage of sales to your five largest customers increased? \\
\hline \multicolumn{2}{|l|}{ Market competitiveness } \\
\hline Number of competitors & $\begin{array}{l}\text { How many competitors do you compete with directly (i.e., as serious or major } \\
\text { competitors) in the market(s) you serve? }\end{array}$ \\
\hline Combined market share competitors & $\begin{array}{l}\text { Can you give your best estimate of the combined percentage market share of your major } \\
\text { competitors? }\end{array}$ \\
\hline \multicolumn{2}{|l|}{ Organizational performance } \\
\hline Mean growth rate $1992-1996$ & Data obtained from official records lodged with Companies House \\
\hline Mean growth rate $1996-2001$ & Data obtained from official records lodged with Companies House \\
\hline End-of-period status & Data obtained from official records lodged with Companies House \\
\hline \multicolumn{2}{|l|}{ Control variables } \\
\hline Current sales turnover & Data obtained from official records lodged with Companies House. \\
\hline
\end{tabular}


Table 2 continued

\begin{tabular}{ll}
\hline Concepts/variables & Sources/questions \\
\hline Return on capital & Data obtained from official records lodged with Companies House. \\
UK location & Classified by the address of the respondent. \\
Firm age & In what year was your business established? \\
Firm size & How many full-time employees work for this company and its wholly-owned \\
& subsidiaries in the UK? \\
Manufacturing sector & Standard classification \\
Services sector & Standard classification \\
\hline
\end{tabular}

strategies and the three external environment dimensions, respectively. We measured each management strategy with three item scores, and each external environment variable with two questionnaire items. The last part of Table 2 presents the control variables that are taken on board; these are included to increase the reliability of estimates of the key relationships by proxying for a few important features of our enterprises that remain at-startup and post-startup. The key control characteristics are broad industrial type (i.e., manufacturing or services), firm age and size, geographical location, and current return on capital and sales turnover.

Finally, we framed the sample deliberately to minimise three sources of variation that could reduce the precision of our empirical estimates: those relating to size, ownership, and legal form, respectively. First, by focusing on medium-sized firms, we restrict the range of variation of performance with respect to firm size. Second, it is known that firm performance is also influenced by ownership (Disney et al. 2003) with, in some instances, enterprises that are part of a larger group outperforming others through their access to economies of scale and scope. Restricting the sample to exclude firms that are subsidiaries minimises this source of variation. Third, because there is evidence that limited liability status is powerfully associated with firm growth (Harhoff et al. 1998), we include only limited companies in the sample.

In 1996, the firms in the database qualify as 'gazelles', having experienced a mean annual sales growth rate between 1992 and 1996 of $36.0 \%$, with a standard deviation of $42.3 \%$. Strikingly, mean annual sales growth slowed dramatically between 1996 and 2001 , with mean annual growth rates of only $8.0 \%$ and a standard deviation of $29.4 \%$. Thus, the gazelle- like growth behaviour of firms in this sample appears to be fragile, having failed to persist over a decade. Clearly, the reason for this cannot be found in a business cycle downturn, as the second period involved perfectly matches the booming Internet era of the late 1990s.

Summary descriptive statistics on growth rates and on the strategy, environment, performance, and structural variables we actually include in our analyses (see below) appear in Table 3. It reveals that our sample is not entirely representative, which we should bear in mind when interpreting our results. In particular, our gazelles operate primarily in business-to-business markets in service industries, with a high reliance on a single product and high managerial ownership, and with an emphasis on new product development. ${ }^{7}$

\section{Modelling firm status and growth}

We model status $z_{i}$ in terms of a vector of firmspecific characteristics, $\mathbf{v}_{i}$, observed in 1996. This vector includes the management strategy, external environment and structural variables described in the previous section. To explain status outcomes in 2001 in terms of $\mathbf{v}_{i}$, we use the multinomial logit model

$P_{j}:=\operatorname{Pr}\left[z_{i}=j\right]=\frac{\exp \left\{\beta_{j}^{\prime} \mathbf{v}_{i}\right\}}{\sum_{m=0}^{4} \exp \left\{\beta_{m}^{\prime} \mathbf{v}_{i}\right\}}$

where the $\beta_{j}$ are vectors of coefficients for each status group $j$. Following conventional practice, we identify

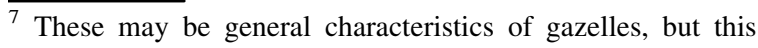
cannot be deduced from our sample, which selected only gazelles in the first place.
} 
Table 3 Summary statistics

\begin{tabular}{|c|c|c|}
\hline Variable & Mean & Standard deviation \\
\hline \multicolumn{3}{|l|}{ Management strategies } \\
\hline \multicolumn{3}{|l|}{ Human resource management } \\
\hline Percentage workforce shares & 0.077 & 0.224 \\
\hline Workforce training & 0.790 & 0.412 \\
\hline Responsibility for HRM & 0.130 & 0.340 \\
\hline \multicolumn{3}{|l|}{ Innovation and technology } \\
\hline Recent innovations as $\%$ of sales $(n=118)$ & 0.187 & 0.238 \\
\hline Developing new product(s) & 0.620 & 0.487 \\
\hline Responsibility for R\&D & 0.440 & 0.498 \\
\hline \multicolumn{3}{|l|}{ Administration and governance } \\
\hline Single enterprise & 0.521 & 0.502 \\
\hline Percentage directors' shares & 0.653 & 0.352 \\
\hline Percentage institutional shares & 0.273 & 0.447 \\
\hline \multicolumn{3}{|l|}{ Marketing and sales } \\
\hline Use of customer surveys & 0.331 & 0.472 \\
\hline Use of customer complaints & 0.264 & 0.443 \\
\hline Use of marketing department & 0.793 & 0.407 \\
\hline \multicolumn{3}{|l|}{ Corporate strategy } \\
\hline Sells to other companies & 0.710 & 0.392 \\
\hline International market & 0.455 & 0.500 \\
\hline Main product as $\%$ of sales $(n=120)$ & 0.827 & 0.256 \\
\hline \multicolumn{3}{|l|}{ External environment } \\
\hline \multicolumn{3}{|l|}{ Market attractiveness } \\
\hline Sales risk $(n=118)$ & 1.891 & 1.276 \\
\hline Past demand growth & 0.686 & 0.466 \\
\hline \multicolumn{3}{|l|}{ Bargaining power } \\
\hline Customer base over 1,000 & 0.388 & 0.489 \\
\hline Increased sales concentration & 0.306 & 0.463 \\
\hline \multicolumn{3}{|l|}{ Market competitiveness } \\
\hline Number of competitors & 0.223 & 0.507 \\
\hline Combined market share competitors & 0.578 & 0.288 \\
\hline \multicolumn{3}{|l|}{ Organizational performance } \\
\hline Mean growth rate $1992-1996$ & 0.360 & 0.423 \\
\hline Mean growth rate 1996-2001 & 0.080 & 0.294 \\
\hline End-of-period status & $-^{\mathrm{a}}$ & n.r. \\
\hline \multicolumn{3}{|l|}{ Control variables } \\
\hline Current sales turnover (in 100 million $£$ ) & 0.321 & 0.304 \\
\hline Return on capital $(n=116)$ & 0.305 & 0.493 \\
\hline UK location: Midlands/East Anglia & 0.240 & 0.429 \\
\hline UK location: South-West/Wales & 0.107 & 0.311 \\
\hline Firm age (pre-1939 company) & 0.132 & 0.340 \\
\hline Firm size (hundreds) & 2.681 & 4.400 \\
\hline Manufacturing sector & 0.215 & 0.412 \\
\hline Services sector & 0.347 & 0.478 \\
\hline
\end{tabular}

All values relate to 1996 , with a sample size of 121 , unless indicated otherwise

a These results are given in Table 4 
the parameters of this model by imposing the normalisation $\beta_{0}=0$. For reasons of interpretability, it is important to be clear what the elements of each $\beta$ vector mean. The ' $k$ 'th element of vector $\beta_{j}$ (for $j>0$ ), i.e., $\beta_{j k}$, measures the impact of the ' $k$ 'th independent variable, $\mathrm{v}_{i k}$, on the log-odds ratio of observing a firm in status group $j$ relative to being liquidated. Thus, a positive coefficient indicates the extent to which the corresponding variable increases the odds of observing a firm in status group $j$ in 2001 rather than in liquidation.

Estimates of the $\beta_{j}$ coefficients are of interest for two reasons. The first is that they can help test if the management strategy, external environment and structural elements of $\mathbf{v}_{i}$ significantly affect firm status. The second reason for the interest in status outcomes is that they might also influence firms' average annual growth rates. For instance, a growth model could be estimated using data on all firms (for which $z_{i}$ takes any value in Eq. 1), or just the subsample of independent survivors, for which $1 \leq z_{i} \leq$ 3 . If survivors have different growth rates than nonsurvivors (i.e., liquidated or acquired firms), then any analysis of growth needs to take account of this in order to avoid potential bias. To this end, we estimate the following sample-selectivity-corrected growth model.

Let $g_{i}$ denote the annual growth rate of firm $i$ 's sales turnover between 1996 and 2001. ${ }^{8}$ Define $\mathcal{T}$ as the total sample of firms for which $g_{i}$ is observable in the 1996-2001 period (i.e., for which at least 2 years of sales turnover data are available). Define $\mathcal{S} \subset \mathcal{T}$ as the sub-sample of firms for which $g_{i}$ is observed and which were still trading independently in 2001. Let $\mathbf{x}_{i}$ denote a vector of firm characteristics observed in 1996 that might affect subsequent growth $g_{i}$, where $\mathbf{x}_{i} \neq \mathbf{v}_{i}{ }^{9}$. The predicted probability that firm $i$ survives to 2001 given its observable characteristics in 1996 is

\footnotetext{
${ }^{8}$ Unlike profitability, which took negative values for several firms in 1996 and 2001, turnover is always non-zero. So the concept of a growth rate is always well defined.

${ }^{9}$ In fact, it is possible to allow $\mathbf{x}_{i}=\mathbf{v}_{i}$ - but then identification of the selectivity-corrected growth equation below depends entirely on assumptions of normal disturbances and correct functional specifications. This is a thin reed indeed on which to base identification (Johnson and DiNardo 1997).
}

$\hat{P}_{i}:=\sum_{j=1}^{3} \frac{\exp \left\{\hat{\beta}_{j}^{\prime} \mathbf{v}_{i}\right\}}{\sum_{m=0}^{4} \exp \left\{\hat{\beta}_{m}^{\prime} \mathbf{v}_{i}\right\}}$.

Define

$\lambda_{i}:=\frac{\phi\left(H_{i}\right)}{\Phi\left(H_{i}\right)}, \quad$ where $\quad H_{i}:=\Phi^{-1}\left(\hat{P}_{i}\right)$,

where $\phi$ and $\Phi$ are the density and distribution functions, respectively, of the standard normal distribution. Then, a sample-selectivity-corrected growth model is

$\mathrm{E}\left[g_{i} \mid \mathbf{x}_{i}, 1 \leq z_{i} \leq 3\right]=\gamma^{\prime} \mathbf{x}_{i}+\theta \lambda_{i} \quad i \in \mathcal{S}$,

where $\gamma$ is a vector of coefficients, and $\theta$ is a scalar, all of which need to be estimated. An appropriate strategy is to use the two-step maximum likelihood and least-squares estimator of Lee (1983) — which is known to be a consistent estimator.

An interesting special case of Eq. 3 occurs if the null hypothesis $H_{0}: \theta=0$ cannot be rejected at conventional significance levels. In this case, it is admissible to estimate a growth equation for all firms-not just survivors:

$\mathrm{E}\left[g_{i} \mid \mathbf{x}_{i}\right]=\gamma^{\prime} \mathbf{x}_{i} \quad i \in \mathcal{T}$,

which can be estimated as a conventional regression.

How can these methods be used in our context? First, if the estimation of either Eqs. 3 or 4 finds statistically significant effects from any of the management strategy, external environment or structural components of the vector of explanatory variables $\mathbf{x}$, then support is provided for their performance effect, taking growth as a measure of firm performance.

Second, to test Gibrat's Law, let $g_{i}$ measure growth over 1996-2001 as before, and define $g_{i,-1}$ as the average growth of firm $i$ over 1992-1996. We now generalise Eq. 3 (and, analogously, Eq. 4) in two ways:

$$
\begin{aligned}
\mathrm{E}\left[g_{i} \mid \mathbf{x}_{i}, 1 \leq z_{i} \leq 3\right]= & \gamma^{\prime} \mathbf{x}_{i}+\theta \lambda_{i}+\zeta g_{i,-1} \\
\mathrm{E}\left[g_{i} \mid \mathbf{x}_{i}, 1 \leq z_{i} \leq 3\right]= & \gamma^{\prime} \mathbf{x}_{i}+\theta \lambda_{i}+\zeta_{1} g_{i,-1} \\
& +\sum_{j=1}^{J} \zeta_{2+j} \cdot\left(g_{i,-1} S_{i j}\right),
\end{aligned}
$$

where $\zeta, \zeta_{1}, \zeta_{2}, \ldots, \zeta_{2+J}$ are coefficients, and $S_{i j}$ is the management strategy variable $j$ (of a total of $J$ ) embodied in $\mathbf{x}_{i}$, i.e., $\left\{S_{i}\right\}_{j=1}^{J} \subset \mathbf{x}_{i}, \forall i$. Equation 5 tests Gibrat's Law directly. If we are unable to reject the 
hypothesis that $\zeta=0$, then Gibrat's Law receives support: firm growth rates are independent. However, this specification does not explicitly allow for firms to adjust their strategies in response to growth, and so break Gibrat's Law. That possibility appears in Eq. 6, which includes a set of interactions between previous growth and new strategies, $g_{i,-1} S_{i j}$, which map on to subsequent growth with coefficients $\left\{\zeta_{2+j}\right\}_{j=1}^{J}$. That is, the interaction terms measure the extent to which strategies covary in response to previous outcomes. Thus, failure of Gibrat's Law implies that $\zeta=0$ in Eq. 5, while at least some of the $\left\{\zeta_{2+j}\right\}_{j=1}^{J}$ coefficients in Eq. 6 are statistically significant, indicating the breakage of Gibrat's Law as a consequence of implementing dynamic management strategies.

Third, to test the extent to which the same explanatory variables significantly affect firm growth across time, slightly different versions of Eqs. 3 and 4 must be estimated. Now let $g_{i}$ denote the average growth rate over 1992-1996, and let $\mathbf{x}_{i}$ denote a vector of explanatory variables observed at 1996 that help determine growth after 1996. Clearly, the strategies and conditions applying in 1996 cannot have directly caused any firm growth observed over 1992-1996, while using data from 1996 captures the notion of a set of inappropriate static strategies being chosen by a firm. If this is the case, there should be no significant effect from $\mathbf{x}_{i}$ on $g_{i}$, i.e., then an $F$-test should be unable to reject the hypothesis that $\gamma=0$.

\section{Results}

For the sake of brevity and clarity, we only report the results for those simple variables (Tables 4, 5, 6, and 7) and interaction variables (Table 6 only) that turned out to be significant at least once in our series of analyses (complete results are available upon request). Thus, the simple and interaction variables that are not associated with any reported result were never significant. This can also be construed as a result in its own right, as it indicates which variables proved to be irrelevant throughout our series of analyses. Below, we highlight what we believe are the main results from our series of analyses.

We first estimated the status model (2); these results are compiled in Table 4. Before turning to the interpretation, we note the impressive statistical performance of the multinomial logit model. The model is highly significant according to a standard likelihood ratio test, emphatically rejecting the null hypothesis that the parameters are jointly zero. And, the fit is good. This is indicated not just by the pseudo- $R^{2}$ of 0.422 , but also by the similarity of the vectors of actual and fitted numbers in each status group (see the bottom two rows of the table). This is especially satisfying, as even well-specified multinomial logit models often fail to predict any cases in some groups (Greene 2003: E19-7). ${ }^{10}$

In the area of corporate strategy, the results are mixed. On the one hand, as far as the firms product portfolio is concerned, having a single dominant product or service in 1996 increases the log-odds of being a large firm in 2001. So, a product core business strategy, by 'sticking to the knitting', pays off nicely, whereas a product diversification-type of policy tends to be counter-productive. On the other hand, trading in an international market in 1996 reduced the $\log$ odds of being a small firm (or acquired) 5 years later. This implies that a geographical diversification strategy, perhaps by searching for foreign markets for the dominant product, reduces the small- and medium-sized gazelles' likelihood of survival. The third corporate strategy coefficient-a business-to-business posture-is not significant. Strikingly, administration and governance, and HRM strategies dropped out altogether in the endperiod status analyses. That is, none of the HRM or administration and governance strategy variables is associated with significant estimates. The latter finding confirms Dalton et al.'s (1998) conclusion that board features are not consistently linked to firm (financial) performance. The impact of the innovation and technology strategy variables on subsequent survival are generally not significantly different from zero, with one exception.

Perhaps surprisingly, gazelles that developed new products for introduction to the market after 1996 were significantly less likely to survive and less likely to be acquired than to be liquidated (see Table 4). This finding might reflect the risk of new product development. Finally, two marketing and sales strategy variables are significant determinants of

\footnotetext{
$\overline{10}$ Note that the Cramer-Ridder pooling test rejected the hypothesis of common coefficients among the three types of independent surviving firms, with $\chi^{2}(51)=115.62(p=$ 0.0001).
} 
Table 4 End-period status in 2001

\begin{tabular}{|c|c|c|c|c|}
\hline Variable & $\begin{array}{l}\text { Survivor Small } \\
(z=1)\end{array}$ & $\begin{array}{l}\text { Survivor Medium } \\
(z=2)\end{array}$ & $\begin{array}{l}\text { Survivor Large } \\
(z=3)\end{array}$ & $\begin{array}{l}\text { Acquired } \\
(z=4)\end{array}$ \\
\hline Constant & 7.787 & 5.884 & 3.424 & 4.752 \\
\hline \multicolumn{5}{|l|}{ Management strategies } \\
\hline \multicolumn{5}{|l|}{ Corporate strategy } \\
\hline \multicolumn{5}{|l|}{ Sells to other companies } \\
\hline International market & $-25.474 * * *$ & $-3.329 *$ & -2.849 & $-3.626^{*}$ \\
\hline Main product as $\%$ of sales & 10.087 & 4.708 & $7.031 *$ & 4.892 \\
\hline \multicolumn{5}{|l|}{ Human resource management } \\
\hline \multicolumn{5}{|l|}{ Percentage workforce shares } \\
\hline \multicolumn{5}{|l|}{ Workforce training } \\
\hline \multicolumn{5}{|l|}{ Responsibility for HRM } \\
\hline \multicolumn{5}{|l|}{ Innovation and technology } \\
\hline \multicolumn{5}{|l|}{ Recent innovations as $\%$ of sales } \\
\hline Developing new product(s) & $-31.324 * * *$ & $-4.449 *$ & $-4.782 *$ & $-5.132 * *$ \\
\hline \multicolumn{5}{|l|}{ Responsibility for $\mathrm{R} \& \mathrm{D}$} \\
\hline \multicolumn{5}{|l|}{ Administration and governance } \\
\hline \multicolumn{5}{|l|}{ Single enterprise } \\
\hline \multicolumn{5}{|l|}{ Percentage directors' shares } \\
\hline \multicolumn{5}{|l|}{ Percentage institutional shares } \\
\hline \multicolumn{5}{|l|}{ Marketing and sales } \\
\hline \multicolumn{5}{|l|}{ Use of customer surveys } \\
\hline Use of customer complaints & $-13.185 * * *$ & -2.562 & $-5.115^{* *}$ & $-3.985 *$ \\
\hline Use of marketing department & -9.562 & $6.979 * * *$ & $7.570 * * *$ & $8.551 * * *$ \\
\hline \multicolumn{5}{|l|}{ External environment } \\
\hline \multicolumn{5}{|l|}{ Market attractiveness } \\
\hline \multicolumn{5}{|l|}{ Sales risk } \\
\hline Past demand growth & 3.708 & -4.652 & $-6.404 * *$ & $-5.170^{*}$ \\
\hline \multicolumn{5}{|l|}{ Bargaining power } \\
\hline Customer base over 1,000 & 9.859 & -30.65 & -3.847 & $-4.267 *$ \\
\hline Increased sales concentration & $13.858 * * *$ & 5.298 & 5.774 & 5.627 \\
\hline \multicolumn{5}{|l|}{ Market competitiveness } \\
\hline \multicolumn{5}{|l|}{ Number of competitors } \\
\hline \multicolumn{5}{|l|}{ Combined market share competitors } \\
\hline Current sales turnover $(100$ million $£)$ & $-53.405 * * *$ & $-11.472 *$ & $-17.803 * *$ & $-11.758 *$ \\
\hline Return on capital & $-22.058 * * *$ & 0.930 & -0.050 & $2.742 * *$ \\
\hline UK location: Midlands/East Anglia & $18.238 * * *$ & 3.234 & 3.602 & 4.248 \\
\hline Firm age (pre-1939 company) & $15.841 * *$ & $-11.355^{* *}$ & -8.883 & $-10.811 * *$ \\
\hline Firm size (hundreds) & $6.102 * * *$ & $3.000 * *$ & $3.163 * *$ & $3.014 * *$ \\
\hline Manufacturing sector & 1.218 & -2.326 & -2.928 & $-3.977^{*}$ \\
\hline Services sector & $-29.918 * * *$ & 2.550 & 1.749 & 1.419 \\
\hline Log-likelihood & -84.227 & & & \\
\hline$\chi^{2}(64)$ & $123.029(p<0.001)$ & & & \\
\hline Pseudo- $R^{2}$ & 0.422 & & & \\
\hline Actual frequency & 10 & 54 & 9 & 32 \\
\hline
\end{tabular}


Table 4 continued

\begin{tabular}{llll}
\hline Variable & $\begin{array}{l}\text { Survivor Small } \\
(z=1)\end{array}$ & $\begin{array}{l}\text { Survivor Medium } \\
(z=2)\end{array}$ & $\begin{array}{l}\text { Survivor Large } \\
(z=3)\end{array}$ \\
\hline Predicted frequency & 12 & 59 & 5 \\
$(z=4)$
\end{tabular}

* Indicates statistical significance of $t$ statistics with a Type I error of $10 \%$;* at $5 \%$; *** at $1 \%$

Method of estimation: multinomial logit. Sample size: 112. Nine observations were discarded because of missing data for at least one variable

No $\log$-odds entries for $z=0$, which is treated as the base group

Estimated standard errors based on robust variance-covariance matrix estimate

subsequent firm status. Companies that relied on customer complaints in 1996 to evaluate the quality of their product or service were significantly less likely to survive as a small or large firm in 2001, or to be acquired. (The results were similar for becoming medium-sized, but nonsignificant.) It may be that the use of customer complaints is primarily a signal of customer dissatisfaction. Firms that had marketing or sales departments in 1996 were significantly more likely to be large or acquired in 2001 than they were to be liquidated. It is likely that an organizational investment in marketing and sales implies an investment in growth, which in turn makes the firm an attractive takeover target. The estimate for the third marketing and sales variable-use of customer surveys-fails to reach significance.

As far as external environment variables are concerned, only three items are associated with at least one significant estimate. For one of these, both bargaining power items have an impact. Having a large customer base (>1,000 customers) in 1996 and having witnessed a growing concentration of sales to a few customers just prior to that time both significantly increase the log-odds of a firm being a small survivor in 2001 relative to being liquidated, and the log-odds of liquidation relative to being acquired. This may reflect the unattractiveness of acquiring firms with complex selling operations. Interestingly, we detected no significant effects of customer base or customer concentration on promoting survival at a larger scale. Firms with large turnovers in 1996 (one of the control variables) were significantly more likely to have been liquidated by 2001 than to have survived with high turnover. This may reflect 'regression to the mean' in firm size, or creative destruction (Greve 1999). Moreover, perhaps surprisingly, firms with growing customer demand in 1996 were significantly less likely to become large or taken over by 2001 , which relates to the market attractiveness dimension. This may be because the greatest demand growth was concentrated among the smallest firms, which do not grow quite fast enough to ultimately shift size group. Alternatively, firms facing growing demand may over-stretch themselves or become victims of a turbulent trading environmentending up in liquidation in either case. The other market attractiveness variables coefficient (sales risk) is insignificant. Actually, estimates for both market competitiveness variables never reach significance. Apparently, the gazelles' competitive environment in 1996 does not impact upon their status in 2001.

Finally, a series of structural variables has a significant impact. First, industrial sector in 1996 played a limited role. Service sector firms are significantly more likely to become liquidated than to become or remain small firms by 2001, though at higher turnover levels there are no strong effects. Being in manufacturing reduced the log-odds of being acquired by 2001, which may reflect the challenge of taking on large specialised enterprises with heavy physical capital liabilities. Also, exit might be more likely in manufacturing, reflecting its continuing decline in the UK. Firms founded before 1939 were significantly more likely to end up as small independent survivors in 2001 than to go into liquidation, but they were also significantly more likely to go into liquidation than to grow into medium-sized enterprises or to be acquired. Firms with high returns to capital in 1996 were significantly more likely to have been acquired than to have been liquidated by 2001 — but they were significantly more likely to have been liquidated than to become small firms. And a firm located in the English Midlands and East Anglia had higher log-odds of surviving with low turnover, all else being equal, than being liquidated. Finally, having a large workforce in 
Table 5 Explaining the average annual growth in sales turnover, 1996-2001 $t$ ratios are based on heteroscedasticity-corrected estimated standard errors. For asterisks, see footnotes to Table 4

\begin{tabular}{|c|c|c|c|}
\hline Variable (observed in 1996) & Coefficient $\gamma$ & $t$ ratio & $\begin{array}{l}\text { Standardised } \\
\text { coefficient }\end{array}$ \\
\hline Constant & 0.152 & 1.579 & \\
\hline \multicolumn{4}{|l|}{ Management strategies } \\
\hline \multicolumn{4}{|l|}{ Corporate strategy } \\
\hline Sells to other companies & $0.178 * *$ & 2.273 & 0.120 \\
\hline \multicolumn{4}{|l|}{ International market } \\
\hline \multicolumn{4}{|l|}{ Main product as $\%$ of sales } \\
\hline \multicolumn{4}{|l|}{ Human resource management } \\
\hline Percentage workforce shares & $-0.233 * *$ & 2.274 & -0.251 \\
\hline \multicolumn{4}{|l|}{ Workforce training } \\
\hline \multicolumn{4}{|l|}{ Responsibility for HRM } \\
\hline \multicolumn{4}{|l|}{ Innovation and technology } \\
\hline \multicolumn{4}{|l|}{ Recent innovations as $\%$ of sales } \\
\hline Developing new product(s) & $-0.093 *$ & 1.713 & -0.052 \\
\hline \multicolumn{4}{|l|}{ Responsibility for R\&D } \\
\hline \multicolumn{4}{|l|}{ Administration and governance } \\
\hline Single enterprise & $-0.097 *$ & 1.827 & -0.054 \\
\hline Percentage directors' shares & $-0.161 * *$ & 2.103 & -0.122 \\
\hline Percentage institutional shares & $-0.114 *$ & 1.654 & -0.069 \\
\hline \multicolumn{4}{|l|}{ Marketing and sales } \\
\hline Use of customer surveys & $0.117 *$ & 1.932 & 0.071 \\
\hline \multicolumn{4}{|l|}{ Use of customer complaints } \\
\hline \multicolumn{4}{|l|}{ Use of marketing department } \\
\hline \multicolumn{4}{|l|}{ External environment } \\
\hline \multicolumn{4}{|l|}{ Market attractiveness } \\
\hline Sales risk & $0.055 * * *$ & 2.674 & 0.011 \\
\hline \multicolumn{4}{|l|}{ Past demand growth } \\
\hline \multicolumn{4}{|l|}{ Bargaining power } \\
\hline \multicolumn{4}{|l|}{ Customer base over 1,000} \\
\hline \multicolumn{4}{|l|}{ Increased sales concentration } \\
\hline \multicolumn{4}{|l|}{ Market competitiveness } \\
\hline \multicolumn{4}{|l|}{ Number of competitors } \\
\hline \multicolumn{4}{|c|}{ Combined market share competitors } \\
\hline UK location: South-West/Wales & $-0.149 * *$ & 2.481 & -0.139 \\
\hline Manufacturing sector & $-0.155 * *$ & 2.340 & -0.103 \\
\hline Log-likelihood & 3.046 & & \\
\hline$F(10,100)$ & $3.790(p<$ & & \\
\hline$R^{2}$ & 0.275 & & \\
\hline
\end{tabular}

1996 is predictably associated with survival in 2001 , especially at higher turnover levels.

Our interpretation of Table 4, thus far, has been across the rows, but a comparison of the columns provides different insights. Four possible status outcomes are identified, with the columns identifying the characteristics that distinguish these outcomes in comparison with the base case of liquidation. For example, the first column $(z=1)$ shows the characteristics of firms most likely to survive, but be small. These are seen to be firms where the growth rates slow sharply after 1996. Such firms are unlikely to be in the service sector and are likely to be older, founded before 1939, and located in the Midlands and 
Table 6 Explaining annual growth in sales turnover, 1996-2001

\begin{tabular}{|c|c|c|c|c|}
\hline \multirow[t]{2}{*}{ Variable (observed in 1996) } & \multicolumn{2}{|l|}{ Model 1} & \multicolumn{2}{|l|}{ Model 2} \\
\hline & Coefficient & $t$ ratio & Coefficient & $t$ ratio \\
\hline Constant & $0.174 *$ & 1.835 & 0.179 & 1.278 \\
\hline Lagged growth & -0.091 & 1.159 & -0.039 & 0.143 \\
\hline \multicolumn{5}{|l|}{ Management strategies } \\
\hline \multicolumn{5}{|l|}{ Corporate strategy } \\
\hline Sells to other companies & $0.170 * *$ & 2.301 & $0.167 * *$ & 2.275 \\
\hline \multicolumn{5}{|l|}{ International market } \\
\hline \multicolumn{5}{|l|}{ Main product as $\%$ of sales } \\
\hline \multicolumn{5}{|l|}{ Human resource management } \\
\hline Percentage workforce shares & $-0.235 * *$ & 2.382 & 0.018 & 0.155 \\
\hline \multicolumn{5}{|l|}{ Workforce training } \\
\hline \multicolumn{5}{|l|}{ Responsibility for HRM } \\
\hline Lagged growth $\times$ workforce shares & & & $-0.832 * * *$ & 3.401 \\
\hline \multicolumn{5}{|l|}{ Innovation and technology } \\
\hline \multicolumn{5}{|l|}{ Recent innovations as $\%$ of sales } \\
\hline Developing new product(s) & $-0.095^{*}$ & 1.774 & -0.202 & 1.627 \\
\hline \multicolumn{5}{|l|}{ Responsibility for R\&D } \\
\hline \multicolumn{5}{|l|}{ Administration and governance } \\
\hline Single enterprise & $-0.104 *$ & 1.899 & $-0.155^{* *}$ & 2.206 \\
\hline Percentage directors' shares & $-0.150 *$ & 1.880 & -0.129 & 0.887 \\
\hline Percentage institutional shares & $-0.117 *$ & 1.659 & -0.215 & 1.507 \\
\hline \multicolumn{5}{|l|}{ Marketing and sales } \\
\hline Use of customer surveys & & & $0.215^{*}$ & 1.785 \\
\hline \multicolumn{5}{|l|}{ Use of customer complaints } \\
\hline Use of marketing department & $0.122 * *$ & 2.015 & & \\
\hline \multicolumn{5}{|l|}{ External environment } \\
\hline \multicolumn{5}{|l|}{ Market attractiveness } \\
\hline Sales risk & & & $0.057 * * *$ & 2.840 \\
\hline \multicolumn{5}{|l|}{ Past demand growth } \\
\hline \multicolumn{5}{|l|}{ Bargaining power } \\
\hline Customer base over 1,000 & $0.061 * *$ & 2.622 & & \\
\hline \multicolumn{5}{|l|}{ Increased sales concentration } \\
\hline \multicolumn{5}{|l|}{ Market competitiveness } \\
\hline \multicolumn{5}{|l|}{ Number of competitors } \\
\hline \multicolumn{5}{|l|}{ Combined market share competitors } \\
\hline UK location: South-West/Wales & & & -0.215 & 1.507 \\
\hline \multirow[t]{3}{*}{ Manufacturing sector } & & & $-0.159 * *$ & 2.431 \\
\hline & $-0.144 * *$ & 1.659 & & \\
\hline & $-0.143 * *$ & 2.322 & & \\
\hline Log-likelihood & 4.512 & & 9.397 & \\
\hline$F$ & $3.740 * * *$ & & $3.120 * * *$ & \\
\hline$R^{2}$ & 0.294 & & 0.353 & \\
\hline
\end{tabular}

$t$ ratios based on heteroscedasticity-corrected estimated standard errors. For asterisks, see notes to Table 4 
Table 7 Explaining the average annual growth in sales turnover, 1992-1996 $t$ ratios are based on heteroscedasticity-corrected estimated standard errors. For asterisks, see notes to Table 4

\begin{tabular}{|c|c|c|c|}
\hline Variable (observed in 1996) & Coefficient $\gamma$ & $t$ ratio & $\begin{array}{l}\text { Standardised } \\
\text { coefficient }\end{array}$ \\
\hline Constant & $0.450 * * *$ & 4.001 & \\
\hline \multicolumn{4}{|l|}{ Management strategies } \\
\hline \multicolumn{4}{|l|}{ Corporate strategy } \\
\hline Sells to other companies & $0.0001 * * *$ & 2.625 & 0.041 \\
\hline \multicolumn{4}{|l|}{ International market } \\
\hline \multicolumn{4}{|l|}{ Main product as $\%$ of sales } \\
\hline \multicolumn{4}{|l|}{ Human resource management } \\
\hline Percentage workforce shares & -0.028 & 0.241 & -0.115 \\
\hline \multicolumn{4}{|l|}{ Workforce training } \\
\hline \multicolumn{4}{|l|}{ Responsibility for HRM } \\
\hline \multicolumn{4}{|l|}{ Innovation and technology } \\
\hline \multicolumn{4}{|l|}{ Recent innovations as $\%$ of sales } \\
\hline Developing new product(s) & -0.063 & 0.845 & 0.000 \\
\hline \multicolumn{4}{|l|}{ Responsibility for $\mathrm{R} \& \mathrm{D}$} \\
\hline \multicolumn{4}{|l|}{ Administration and governance } \\
\hline Single enterprise & -0.082 & 0.994 & -0.024 \\
\hline Percentage directors' shares & 0.000 & 0.302 & 0.000 \\
\hline Percentage institutional shares & -0.075 & 0.984 & 0.000 \\
\hline \multicolumn{4}{|l|}{ Marketing and sales } \\
\hline Use of customer surveys & 0.038 & 0.425 & 0.073 \\
\hline \multicolumn{4}{|l|}{ Use of customer complaints } \\
\hline \multicolumn{4}{|l|}{ Use of marketing department } \\
\hline \multicolumn{4}{|l|}{ External environment } \\
\hline \multicolumn{4}{|l|}{ Market attractiveness } \\
\hline Sales risk & $0.003 * * *$ & 3.950 & -0.027 \\
\hline \multicolumn{4}{|l|}{ Past demand growth } \\
\hline \multicolumn{4}{|l|}{ Bargaining power } \\
\hline \multicolumn{4}{|l|}{ Customer base over 1,000} \\
\hline \multicolumn{4}{|l|}{ Increased sales concentration } \\
\hline \multicolumn{4}{|l|}{ Market competitiveness } \\
\hline \multicolumn{4}{|l|}{ Number of competitors } \\
\hline \multicolumn{4}{|c|}{ Combined market share competitors } \\
\hline UK location: South-West/Wales & -0.004 & 0.062 & -0.102 \\
\hline Manufacturing sector & 0.082 & 0.672 & 0.467 \\
\hline Log-likelihood & -64.296 & & \\
\hline$F(10,100)$ & $0.520(p=$ & & \\
\hline$R^{2}$ & 0.045 & & \\
\hline
\end{tabular}

East Anglia. They tend to be larger employers, but with low sales, implying low productivity.

However, it is the strategy of such firms that is interesting since they tend to be strongly dependent upon international markets, have many customers, and operate in markets where sales concentration was recognised as rising sharply in 1996. Their response to these threats, even in 1996, would seem to have been counterintuitive. For example, they were very unlikely to use customer complaints as a measure of the quality of their product/service, they were unlikely to have a marketing department, and they were very unlikely to be developing a new product. Not surprisingly, their return on capital is low. In 
short, these firms exhibit many of the characteristics of a 'trundler'-defined as a slow-growing but (just) surviving company, even though many of these characteristics were observed after a period of very rapid growth. In this sense, these firms may have reverted to another 'type' after an unusual period of high growth.

The interesting contrast is with the firms in the third column $(z=3)$. This column compares the firms that not only survived but which were also large in 2001. These can be considered as surviving firms that continued to grow rapidly but were not acquired. These are arguably the 'true' gazelles. Perhaps surprisingly, the third column shows that the gazelles do not seem to have radically different strategies from those of the 'trundlers'. They tend to have larger workforces but lower sales, and they are also unlikely to be developing new products or to be using customer complaints as a measure of quality. Where they differ from the 'trundlers' is in being more likely to have a marketing department, in having slower demand growth prior to 1996 and in having a main product that is a major contributor to sales. It should be noted that dependency upon international markets is not a characteristic of gazelles in this sample.

The final column $(z=4)$ shows the company characteristics associated with being acquired, relative to being liquidated. Some of these findings are as one might have expected. Acquisition is more likely to have occurred where the company is young, rather than old, and less likely when it is in manufacturing, rather than services. The presence of a marketing department also has a positive impact. Perhaps more surprising is that these acquired firms are those that are less likely to use customer complaints as a measure of quality, or to sell heavily in international markets, or to be developing a new product. They also have a smaller customer base, on average. Our interpretation of these mixed findings for the acquired group reflects the mixture of motivations for the acquisition of such businesses. In some instances, it may reflect a wish to negate the influence of a potentially powerful competitor; in others, it may be to acquire some element of a poorly performing enterprise. Pre-acquisition performance is therefore likely to reflect this variety.

Finally, it is interesting to infer some characteristics of companies that are liquidated in comparison with those that survive or are acquired. It is clear that the non-survivors are smaller in terms of employment, but apparently more likely to be selling in international markets, more likely to be developing a new product, and more likely to be using customer complaints as a measure of quality. None of the latter three characteristics are normally associated with poor performance. Jointly, they may reflect risky strategies that are associated with substantial customer dissatisfaction.

Next, we estimated the sales turnover growth model (3), using data from 1996-2001, for the sample of surviving independent firms only. The coefficient on the sample selectivity term was found to be insignificant: $\hat{\theta}=-0.062$, with an absolute $t$ ratio of $0.828(p=0.417) .^{11}$ Thus, the average turnover growth rates of firms that survived independently for the 5 years following 1996 are not significantly different from those of firms that did not. For the most part, the 'survivors only' sample and the broader sample of all firms also had similar determinants.

The finding of insignificant sample selectivity allowed us to utilise the complete sample of all firms, i.e., to estimate Eq. 4. A general-to-specific estimation strategy yielded the parsimonious growth equation reported in Table 5. This is statistically significant and shows a reasonable goodness-of-fitespecially when compared with previous estimates of firm employment growth equations (see, for example, Westhead and Cowling 1995). Table 5 presents, for the set of statistically significant variables, the estimated $\gamma$ coefficients, $t$ ratios, and standardised coefficients. $^{12}$

What is striking about Table 5 is the relatively small number of statistically significant determinants of growth compared with the large number included at the outset of the general-to-specific modelling exercise. The most notable insignificant variables are: (1) average annual growth rates in the 5 years prior to 1996 ( $p=0.795$; see Table 6); (2) the size of the initial customer base $(p=0.353)$ and its growth in the recent past $(p=0.517)$; (3) initial turnover

\footnotetext{
11 A very similar result was obtained when survivors were pooled at the first stage: $\hat{\theta}=-0.069,|t|=-0.758$, and $p=0.430$. Standard errors here are based on the selectivitycorrected covariance matrix described by Lee (1983).

12 Standardised coefficients are estimated after centering all variables around their mean and then dividing them by their standard deviation. They permit the relative economic significance of a variable to be evaluated.
} 
$(p=0.154) ; \quad$ and (4) initial employment size $(p=0.677)$. In short, past success or scale is no guide to future success. Second, gazelles that continue to grow are insensitive both to the number of competitors $(p=0.492)$ and to new product development ( $p=0.827)$. Third, it makes no difference to subsequent growth whether the firm's customers are households or other firms $(p=0.495)$. Fourth, subsequent growth is observed in firms in all industrial sectors, whether or not they operate in national or international markets. Finally, workforce training, share ownership and directorship structure, being a single enterprise rather than part of a group, having a sales or marketing department, regional location and age were also insignificant determinants of future growth ( $p \geq 0.15$ in all cases).

However, three of the five groups of management strategies play a significant role in explaining company growth. In all areas except for administration and governance, only one item turned out to be significant in each group: high-growth firms tend to avoid issuing shares to workers (HRM strategy), to avoid developing new products or services (innovation and technology strategy), to conduct market research in the form of customer surveys (marketing and sales strategy) and to sell to other companies rather than to customers directly (corporate strategy). In contrast, all three administration and governance items are significant: fast-growing firms are also more likely to be part of a group than exist as a single corporate body, and they are less likely to issue shares to directors or outside investors.

As far as the external environment estimates are concerned, only one item produces a significant coefficient: the sales risk item of the market attractiveness dimension is positively associated with annual sales turnover growth in 1996-2001. Apparently, fast-growing firms experience a greater variation in sales turnover. The latter finding is consistent with there being a risk-return trade-off: firms only take above-average risks if they anticipate aboveaverage payoffs. Apart from that, the external environment does not produce any significant influence on sales turnover growth. Management strategy is apparently a much more important driver of the gazelles' growth performance than the external environment. Two structural variables are associated with significant coefficient estimates. First, highgrowth firms are predominantly based outside the manufacturing sector. Second, they are primarily located outside the South West of England and Wales.

As well as these all being statistically significant influences, some factors are also fairly substantial in economic terms. According to the column of standardised coefficients, the most substantial negative influences on subsequent growth are (1) starting a workforce share ownership scheme, followed by (2) being located in the South West or Wales, and (3) issuing shares to directors. This result suggests that location is important for sustaining high-growth gazelle behaviour, as is the retention of control rights by the owner. The latter finding contrasts with some 'classic' warnings in the literature that future entrepreneurial growth can be jeopardised by egocentric entrepreneurs retaining control instead of 'handing over the reins' of the business to others (Morris et al. 1997). In contrast, the standardised coefficient for sales risk is relatively small, suggesting that although the risk-return trade-off is present, it is not quantitatively very important.

Next, we provide an exploratory test of Gibrat's Law by estimating Eqs. 5 and 6. Here, we estimate two models: Model 1 includes static management strategies (main effects) only, while Model 2 adds dynamic management strategies (interaction effects). The results are compiled in Table 6 (recall that only the significant interaction effects are reported). The results obtained using Model 1 indicate that, without controlling for dynamic management strategies, the average growth rate over the 5 years prior to 1996 (called 'lagged growth') is insignificant-implying that Gibrat's Law cannot be rejected. In contrast, the findings obtained using Model 2 show that lagged growth becomes statistically significant when interacted with shares held by the workforce. Thus, growth rates in different periods are no longer independent, thereby confuting Gibrat's Law. These results support the argument that the use of dynamic management strategies by firms can explain the empirical breakdown of Gibrat's Law.

Finally, related to this, we argued that the adoption of static 'best practice' management strategies would not increase a firm's growth rate. One simple way of testing this hypothesis is to take the set of variables that were shown to be significant determinants of growth over 1996-2001 period and to check whether they also explained growth in the earlier 1992-1996 
period. If it is found that they do, then one could conclude that a 'static' policy of replicating the strategies and conditions observed to be conducive to success in one period (in our study 1992-1996) can work in other periods (i.e., until 2001) as well. The results are shown in Table 7.

First, it is clear that the explanatory power of the growth regression is much weaker in Table 7 than in Table 5, as reflected in the low $R^{2}$ value of 0.045 . The $F$ statistic of 0.52 is not statistically significant $(p=0.87)$. In effect, the explanatory power of the management strategy variables is reduced dramatically. The only management strategy variable that appears to be significant is 'Sells to other companies' (corporate strategy) which, unlike in Table 5, has an insubstantial (near zero) effect. The other significant variable in Table 7 is an external environment one'Sales risk' (market attractiveness)-implying, as before, that firms with wide year-to-year fluctuations in their sales growth grow more rapidly than those where the growth is more consistent. Again, the effect is quantitatively much smaller in Table 7 than it is in Table 5. Taken as a whole, these results are broadly supportive of our argument that the best practices logic does not hold. Only one best practice management strategy variable from the 1996-2001 analysis was associated with rapid growth in the 1992-1996 period. Clearly, the same variables do not appear to exert a consistent influence in different time periods. This finding cautions against using the lessons learnt from one period and applying them without modification in a different time period.

Of course, the analysis just conducted can be no more than exploratory. After all, much of our data is static in nature, based on a single cross-section derived from a one-off questionnaire, and the above analysis has implicitly assumed that in the 5-year period after the questionnaire was commissioned, there were no major shifts in strategy, on average. Given the large body of literature on organisational inertia (for a recent overview, see van Witteloostuijn et al. 2003), this assumption is not unrealistic. As is well known from empirical studies of organisational change, major strategic re-orientations are exceptions rather than the rule, particularly over short time spans (see the review chapters on change in Baum 2002). However, only with a repeated-measures research design can we check the validity of our assumption of relative strategic inertia.

\section{Conclusion}

The central question posed by this paper is whether the clear presence and economic significance of gazelles is compatible with Gibrat's Law or, instead, whether it reflects the expectations of the strategic management literature. To address this we argued for the importance of dynamic rather than static management strategies, with the latter suggesting that adopting the 'best practice' policies of one period is counter-productive in a later period. We find this insight helpful in charting the performance of medium-sized British gazelles and in understanding:

1. why some, but not all, the implications of Gibrat's Law of random firm growth are valid;

2. which strategy and environmental variables have a predictable influence on firm performance; and

3. why the routine application of static 'best practice strategies' is unlikely to foster firm growth in a changing environment.

The key evidence compatible with Gibrat's Law is that gazelles have difficultly sustaining their frenzied pace of growth. The mean annual sales growth of gazelles between 1992 and 1996 was 36\%, but surviving gazelles grew by just $8 \%$ between 1996 and 2001. Thus, gazelle-like growth appears to be fragile, having failed to persist over a decade, even in a period of impressive macroeconomic growth, such as the late 1990s.

However, there are key strategies that seem to help gazelles to become or remain large (in terms of turnover). Two of these are having both a marketing department and a main product that is a major contributor to sales. Interestingly, large gazelles also avoided both new product development and using customer complaints as a form of quality control. When measuring organisational performance in terms of growth, successful strategies were found to include using customer surveys, selling to other companies rather than to customers directly, avoiding issuing shares to the workers, directors or other outside investors, and refraining from developing new products or services. Most powerfully of all, we showed that firms are unlikely to be successful if they attempt to draw lessons from observing growth in one period and applying these lessons routinely at a different point in time. 
One explanation for these findings is that an inappropriate mix of strategies was to blame. Sustained growth over a long period requires the timely adaption of strategies, both externally and internally. Organisational ecology's assumption of organisational inertia (Hannan and Freeman 1984; Carroll and Hannan 2000) could then apply to our sample of gazelles, with high-growth Middle-Market firms developing routinised strategies which were reinforced by their early association with rapid growth. To change such routinised strategies after a period of positive performance feedback is anything but easy, as is clear from research into strategic momentum (Amburgey et al. 1993; Greve 1999). The extent to which some gazelles adopted inappropriate rules of thumb-for example, by launching worker profitsharing schemes-emphasises that such strategies are unlikely to be successful.

An important finding is that those gazelles which continue to grow rapidly are those which are least likely to sell shares to others, including members of the workforce, directors and venture capitalists. Of course, this begs the question about why worker share ownership schemes, for example, often fail to deliver growth-in contrast to what many regard as the 'received wisdom'. While further research is needed to provide definitive answers to this question, one can hazard several guesses. It might be that such schemes involve management losing control or that workers received a sufficiently large 'income effect' that incentives to supply high effort are blunted. Our favoured explanation is that the gazelles' owners have specialist inside knowledge about the expected future performance of the business. In short, it seems plausible that the owners who know that the business will succeed are prepared to 'bootstrap' (Winborg and Landstrom 2001) so as to avoid having to sell and, consequently, share future value. Only owners who are either more uncertain or who know that the business will not perform as well actually sell their shares. Clearly, these are just tentative suggestions, and further research is needed to consolidate these findings in different industry and country settings.

Other avenues for research also remain wide open in this field. Rapid-growth Middle-Market firms are a vital element of modern economies, being important 'job-producing machines'. Understanding what drives the sustained growth success of such firms over many years is therefore essential. In particular, what explains our findings that only a small subset of gazelles is successful in jumping over the barriers to sustained growth, while so many other promising Middle-Market gazelles return to more normal growth rates? To be able to answer this question, one other research avenue is particularly promising. A multi-dimensional, large-scale and system-type fit study has to identify the many pieces of the performance puzzle and then determine how they work together in producing rapid growth (see Parker and van Witteloostuijn 2009, for a novel method as to how to do this). This can only take place within a truly dynamic study, with repeated measures in a longitudinal context.

Acknowledgements The data used in this research derive from work on Ten Percenters by Deloitte and Touche (D\&T). The authors would like to express their appreciation to Peter Morgan, David Wemborn and Tina Hene at D\&T who have facilitated and contributed to this research over many years. The considerable contribution of Nick Spencer is also very much appreciated, but the authors alone are responsible for the interpretations provided. Arjen van Witteloostuijn gratefully acknowledges the financial support of the Flemish Science Foundation (FWO).

Open Access This article is distributed under the terms of the Creative Commons Attribution Noncommercial License which permits any noncommercial use, distribution, and reproduction in any medium, provided the original author(s) and source are credited.

\section{References}

Acs, Z. J., \& Mueller, P. (2008). Employment effects of business dynamics: Mice, gazelles and elephants. Small Business Economics, 30, 85-100.

Acs, Z. J., Parsons, W., \& Tracy, S. (2008). High impact firms: Gazelles re-visited. Washington D.C.: Small Business Administration.

Almus, M. (2002). What characterizes a fast growing firm? Applied Economics, 34, 1497-1508.

Amburgey, T. L., Kelly, D., \& Barnett, W. P. (1993). Resetting the clock: The dynamics of organizational change and failure. Administrative Science Quarterly, 38, 51-73.

Baum, J. A. C. (Ed.). (2002). Companion to organizations. Oxford: Blackwell Publishers.

Bishop, K., Mason, G., \& Robinson, C. (2009). Firm growth and its effects on economic and social outcomes: Literature and statistical review. Report to the National Endowment for Science Technology and the Arts. London: NIESR.

Carroll, G. R., \& Hannan, M. T. (2000). The demography of corporations and industries. Princeton, NJ: Princeton University Press.

Coad, A. (2009). The growth of firms: A survey of theories and empirical evidence. Cheltenham: Edward Elgar. 
Dahlqvist, J., Davidsson, P., \& Wiklund, J. (2000). Initial conditions as predictors of new venture performance: A replication and extension of the Cooper et al. study. Enterprise and Innovation Management Studies, 1, 1-17.

Daily, C. M., McDougall, P. P., Covin, J. G., \& Dalton, D. R. (2002). Governance and strategic leadership in entrepreneurial firms. Journal of Management, 28, 387-412.

Dalton, D. R., Daily, C. M., Ellstrand, A. E., \& Johnson, J. L. (1998). Meta analytic reviews of board composition, leadership structure and performance. Strategic Management Journal, 19, 211-217

Davidsson, P., Achtenhagen, L., \& Naldi, L. (2007). What do we know about small firm growth? In S. C. Parker (Ed.), The life cycle of entrepreneurial ventures (pp. 361-398). New York: Kluwer.

Davidsson, P., Kirchhoff, B., Abdulnasser, H.-J., \& Gustavsson, H. (2002). Empirical analysis of business growth factors using Swedish data. Journal of Small Business Management, 40, 332-349.

Delmar, F., Davidsson, P., \& Gartner, W. B. (2003). Arriving at the high growth firm. Journal of Business Venturing, 18, 189-216.

Disney, R., Haskel, J., \& Heden, Y. (2003). Restructuring and productivity growth in UK manufacturing. Economic Journal, 113, 666-694.

Garnsey, E., Stam, E., Heffernan, P. (2006). New firm growth: exploring processes and paths. Industry and Innovation, $13,1-20$.

Gibrat, R. (1931). Les inéqalités économique. Paris: Recueil Sirey.

Greene, W. H. (2003). Economic analysis (5th edn). New Jersey: Prentice-Hall.

Greve, H. R. (1999). The effect of core change on performance: Inertia and regression toward the mean. Administrative Science Quarterly, 44, 590-614.

Hannan, M. T., \& Freeman, J. (1984). Structural inertia and organizational change. American Sociological Review, 49, 149-164.

Harhoff, D., Stahl, K., \& Woywode, M. (1998). Legal form, growth and exit of West German firms: Empirical results for manufacturing, construction, trade and service industries. Journal of Industrial Economics, 66, 453-488.

Hart, P. E., \& Oulton, N. (1996). Growth and size of firms. Economic Journal, 106, 1242-1252.

Henrekson, M., \& Johansson, D. (2009). Gazelles as job creators. Small Business Economics. doi:10.1007/s11187-0099172-Z.

Honjo, Y. (2004). Growth of new start up firms: Evidence from the Japanese manufacturing industry. Applied Economics Letters, 11, 21-32.

Hull, L., \& Arnold, R. (2008). New Zealand firm growth as change in turnover. Wellington, NZ: Ministry of Economic Development.

Huselid, M. (1995). The impact of human resource management practices on turnover, productivity, and corporate financial performance. Academy of Management Journal, $38,635-672$.

Itami, H., \& Numagami, T. (1992). Dynamic interaction between strategy and technology. Strategic Management Journal, 13, 119-135.

Johnson, J., \& DiNardo, J. (1997). Econometric methods (4th edn). New York: McGraw Hill.
Jovanovic, B. (2001). New technology and the small firm. Small Business Economics, 16, 53-55.

Kangasharju, A., \& Pekkala, S. (2002). The role of education in self-employment success in Finland. Growth and Change, 33, 216-237.

Lee, M. (1983). Generalised econometric models with selectivity. Econometrica, 51, 507-12.

Littunen, H., \& Tohmo, T. (2003). The high growth in new metal-based manufacturing and business service firms in Finland. Small Business Economics, 21, 187-200.

Lotti, F., Santarelli, E., \& Vivarelli, M. (2009). Defending Gibrat's law: A long term regularity. Small Business Economics, 32, 31-44.

Matsuno, K., Mentzer, J. T., \& Özsomer, A. (2002). The effects of entrepreneurial proclivity and market orientation on business performance. Journal of Marketing, 66, 18-32.

McGahan, A. M., \& Porter, M. E. (2003). The emergence and sustainability of abnormal profits. Strategic Organization, 1, 79-108.

Moreno, A. M., \& Castillas, J. C. (2007). High growth SMEs versus no-high growth SMEs. Entrepreneurship and Regional Development, 19, 69-88.

Morris, M. H., Williams, R. O., Allen, J. A., \& Avila, R. A. (1997). Correlates of success in family business transitions. Journal of Business Venturing, 12, 385-401.

Naman, J. L., \& Slevin, D. P. (1993). Entrepreneurship and the concept of fit: a model and empirical tests. Strategic Management Journal, 14, 137-153.

Parker, S. C., \& van Witteloostuijn, A. (2009). A general framework for estimating multidimensional contingency fit. Organization Science, 14. doi:10.1287/orsc.1090.0464.

Peters, T., \& Waterman, R. (1982). In search of excellence. London: Profile Books.

Schutjens, V. A. J. M., \& Wever, E. (2000). Determinants of new firm success. Papers in Regional Science, 79, 135-153.

Singh, A., \& Whittington, G. (1968). Growth, profitability and valuation. Department of Applied Economics, University of Cambridge, Occasional Paper, No 7. Cambridge: Cambridge University Press.

Slater, S. F., \& Olson, E. M. (2001). Marketing's contribution to the implementation of business strategy: An empirical analysis. Strategic Management Journal, 22, 1055-1067.

Smallbone, D., Leigh, R., \& North, D. (1995). The characteristics and strategies of high growth SMEs. International Journal of Entrepreneurial Behaviour \& Research, 1, 44-62.

Sorge, A. M., \& van Witteloostuijn, A. (2004). The (non)sense of organizational change: An essai about universal management hypes, sick consultancy metaphors and healthy organization theories. Organization Studies, 25, 12051231.

Stam, E., \& Wennberg, K. (2009). The roles of R \& D in new firm growth. Small Business Economics, 33, 77-89.

Storey, D. J. (1994). Understanding the small business sector. London: ITP.

Storey, D. J. (2003). Education, training and development policies and practices in medium-sized companies in the UK: do they really influence firm performance? Omega, 30, 249-264.

Sutton, J. (1997). Gibrat's legacy. Journal of Economic Literature, 35, 40-59. 
Wagner, J. (1992). Firm size, firm growth, and the persistence of chance: Testing Gibrat's Law with establishment data for Lower Saxony, 1978-1989. Small Business Economics, 4, 125-132.

Westhead, P., \& Cowling, M. (1995). Employment change in independent owner-managed high-technology firms in Great Britain. Small Business Economics, 7, 111-140.

Wiklund, J., Patzelt, H., \& Shepherd, D. A. (2009). Building an integrative model of small business growth. Small Business Economics, 32, 351-374.
Winborg, J., \& Landstrom, H. (2001). Financial bootstrapping in small businesses: examining small business managers resource acquisition behaviours. Journal of Business Venturing, 16, 235-254.

van Witteloostuijn, A., Boone, C., \& van Lier, A. (2003). Toward a game theory of organizational ecology: Production adjustment costs and managerial growth preferences. Strategic Organization, 1, 259-300. 